moderns have afforded profitable or curious in reference to Physick, that they who shall read this may spare themselves the pains of reading any other." With much, of course, that is laughable to us in our day, there are the elements of truths, and, above all, the idea of progress. "There are," he says, "three sorts of vertues attributed to Medicaments. The first sort, which by the antients were esteemed elementary, and only ought to be attributed to the principles whereof it is composed ; that is, that it heats, cools, moistens, and dries. The second qualities are the products of the first ; for the property of heat is to open, rarefie, attenuate, attract and so on. The third qualities are hidden, and we can only find them out by experience, as when a Jasper apply'd to a wound stops the blood; when a Toad dry'd, being held in the hand, stays bleeding at the nose, and assuages the tooth ache, which is also performed by the bone in the foreleg of the same Toad; when a stick of Ash boyled under a certain constellation, stops all losses of blood ; when a Hazelstick, gathered in its proper season, heals all contusions; when the Eagle-stone, hung about the neck, hinders abortion, and hastens and facilitates birth, being ty'd to the thigh, . . . and several other effects of the same nature, of which Philosphers labour to give the matural reason."

The philosophers probably had some difficulty in explaining the advantage of the oil of scorpions, made by plunging into boiling oil sixty of the fairest and most vigorous live scorpions that can be got, though it was said to have the power of dissolving renal or vesical calculi; or of the lozenges of vipers, used in malignant fevers ; or of the forty-eight ingredients in the Mithridate of Democrates for procuring rest; or of the sixty-three ingredients in the treacle of Andromachus the elder; or even of the shavings of man's skull, which formed an important element in the composition of an anti-epileptic water. Such illustrations of the therapeutics of a bygone day serve only to raise a smile. But the principle of reasoning should be, and is, the same for us as for our queer old writer of two centuries ago : first, the observations of experience; and secondly, the labour of the philosophers - the deduction from the experimental data. And not thus only. Although Bacon has stigmatised the doctrine of final causes as "barren like a virgin consecrated to God that can bear no fruit," yet Harvey avowedly owed his great discovery to that very doctrine, and much of Sir Charles Bell's best work was done in enthusiastic admiration of the same principle.

Much of what seems unscientific in our practice depends upon the very anxiety for our patient's life. In fever, for example, one may think the poison itself the all-important element, and in treatment may favour elimination; another may fear lest the high temperature may destroy life, and use all his energy towards its reduction; another may watch the patient's strength, and do little but feed or stimulate. In all the result may be good. In all, paradoxical as it may sound, a real step forward has been made towards scientific therapeutics. But when in ague we see the pyrexia, the splenic enlargement, and the absence of urea in the urine-and by quinine treatment the subsidence of all pyrexia, the diminution in the volume of the spleen, and the reappearance of urea, it is impossible to deny that here our therapeutics are scientific. Nay, more! by means of our therapeutics, we are nearer an accurate understanding of the morbid phenomena.

The same may be said of other diseases, of the pathological anatomy of which we know little or nothing. We can often treat with succes affections such as epilepsy, chorea, delirium tremens, spinal irritation, and that strange spinal jar with which we are now so conversant as the result of railway accidents. It is not too much to say that the therapeutics of these affections have shed some light on the nature of the affections themselves. Such examples might be multiplied.

The action of diaphoretics, of many diuretics, and of most of the purgatives, the modus oferandi of the alkalies on the urine, of ammonia in the treatment of arterial clot, of the bromides, of strychnia, and $n$ ergot, are all illustrations of advance in our knowledge of scientific therapeutics; whilst at least as much may be said as to the mode of action of several of the sedatives and narcotics.

Experience itself is a scientific factor, on the ground that the same phenomena always occurring under similar conditions form a law. As to what is beyond and above that law, human reasoning will scarcely carry us. But it is incompatible with common sense not to be sure that laws so grand in conception, so minute in detail, necessarily imply the existence of a law-giver. And it seems to me impossible that any physiologist in the highest sense, or any worker in pathology, which is only physiology under different conditions, can be so blind to the plainest teachings of his own science, as to deny the existence of a first cause. Such men are not numerous in our profession; and we shall all agree in some noble words of Lecky, in his Mistory of Rationalism, with which I shall close this address.

"Even scientific men sometimes forget that the discovery of law is not an adequate solution of the problem of causes. When all the mo- tions of the heavenly bodies have been reduced to the dominion of gravitation, gravitation itself still remains an insoluble problem. Why it is that matter attracts matter, we do not know; we perhaps never shall know. Science can throw much light on the laws that preside over the development of life; but what life is, and what is its ultimate cause, we are utterly unable to say. The mind of man, which can track the course of the comet, and measure the velocity of light, has hitherto proved incapable of explaining the existence of the minutest insect, or the growth of the most humble plant. In grouping phenomena, in ascertaining their sequences and their analogies, its achievements have been marvellous ; in discovering ultimate causes it has absolutely failed. The first principle, the dynamic force, the vivifying power, the efficient causes of those successions, which we term natural laws, elude the utmost efforts of our research. We know nothing, or next to nothing, of the relations of mind to matter, either in our own persons or in the world that is around us; and to suppose that the progress of natural science eliminates the conception of a first cause from creation by supplying natural explanations, is completely to ignore the sphere and limits to which it is confined."

\section{OBSERVATIONS ON ALBINISM.*}

\section{By C. S. JEAFFRESON, Esq.}

Surgeon to the Children's Hospital and Eye Infirmary, Newcastle-on-Tyne.

THE condition of the human body which is characterised by the total absence of pigment from the structures in which it is naturally de. posited, and which we term albinism, did not escape the observation of some of the most ancient scientific writers and observers. Thus we find this peculiar condition mentioned by Pliny and Herodotus. Its occurrence was first called attention to amongst the negro races. This is not surprising, when we consider the striking contrast of colour to which in their case it gives rise; and we have adopted the common name of albino from the Portuguese, who first employed it to indicate a white Moor. It was commonly imagined that these white Africans formed a distinct race ; but the more extended observations of recent years have shown that albinos are common to all countries and all races. Pickering mentions their being found in Java, Sumatra, the Fiji Islands, the Isthmus of Darien, and many other places. But, wherever they are found, they conform in all their external appearances except colour to the race from which they sprang; and thus, among the Africans, they have the thick lips and curly hair peculiar to this people. Although albinos do not constitute a special race of mankind, there can be little question that their condition is liable to descend hereditarily to their offspring. This is especially the case when both parents present the same peculiarity; and thus, in countries where albinos are common, families of them may occasionally be seen, the result of marriages between two persons in the same condition. Albino children are so rare in Europe as to render such a combination of circumstances unlikely to occur; and I can find no record of an albino family amongst any of the more civilised countries of our own quarter of the globe.

Although the albino state was recognised at such an early period, it did not attract particular attention till the end of the last century, when it was noticed by Buffon. Blumenbach made it the subject of special study, and pointed out its proximate cause-viz, the deficiency of pigment in the rete mucosum of the skin and other structures in which it is normally present. His olsservations were followed by some interesting papers by Dr. Buzzi of Milan, who had the opportunity of dissecting an albino. He confirmed Blumenbach's views, and further pointed out that in these subjects the rete mucosum was entirely absent. In this, however, he must have been in error; for it is im. possible that the skin could live and grow without the layer of soft and rapidly increasing cells which constitute this membrane, and which provide for the proper reproduction of those parts of the skin which are being daily destroyed as the result of the wear and tear of every-day life.

From this date, the peculiar condition of albinos was looked upon as a disease whose proximate cause was the absence of pigment in the tissues. It is not common to human beings alone, but is found among all the different varieties of warm-blooded animals. Familiar in stances of it exist among rats, mice, rabbits, cats, dogs, and birds of all kinds. Although the proximate cause of albinism has been fully recognised and dwelt upon, its remote cause is still a matter of conjecture. Buffon supposed that it indicated a tendency of the human body to revert to what he considered the natural colour ; and Buzzi observed in two cases that the mother, during the time of conception, had an inordinate desire for milk, which she freq uently gratified. Shockduring the period of gestation, peculiarities in the seminal fluid of 
the parents, and many other conditions, have been alleged as causes; but most of these hypotheses have been advanced without sufficient groundwork of observation and facts, so that we are now as far from recognising the real cause of this condition as we were a century ago. We know that pigment iirst makes its appearance in the structures of the foetus about the sixth or seventh week of conception, where it may be found in the membranes which later form the choroid coat of the eye; subsequently, it is deposited in the rete mucosum; but it is not fully developed in that membrane till after the sixth month. The most probable manner in which light may be thrown upon this in. teresting question is by the study of the varying conditions which influence the deposition of pigment in the structures of the adult and in many of the lower animals. As yet, our knowledge of the difference of pigmental colouring in the human body amounts to this: that, of the five different races, each has its peculiar tint, which, within a certain extent, is liable to slight variations in each race; that, in those who are most intensely coloured, variations in degree are uncommon, but total absence of colour is not uncommon; that the lighter coloured races present greater features of variation, but within well marked limitsfor instance, there is no record of an European ever being born with the same dark tint as the African.

With regard to our special knowledge of pigment, it may be summed up in the following facts. It consists of a fine molecular matter, secreted by certain cells called pigment-cells, which are found in various situations-notably the choroid coat of the eye, the rete mucosum of the skin, certain portions of the nerves and their ganglia, and the dura mater, the roots of the hair, and other situations. In its chemical constitution, pigment consists of melanine, a highly carbonaceous material, closely allied to the fatty compounds. It contains a notable quantity of iron. In intensity of colour, it varies much in the different races of mankind, thus giving rise to one of the most striking and permanent characteristics. In man, and especially in the fairer races, its development is influenced by certain exterior conditions, chiefly consisting of variations of light, heat, and certain internal conditions, such as the pregnant state. In some rare cases, violent emotion and other nervous influences materially affect its development. We further know that in some forms of tumours it makes its appearance in large quantities, and that in disease of the suprarenal capsules the quantity in the skin becomes considerably augmented. From these data, I think we may with fairness infer that pigment, or some material from which the cells are capable of manufacturing it, circulates with the blood; and the large quantity of iron which it contains would lead us to indicate hæmatin as the probable material. Our knowledge of the processes by which the blood is elaborated is as yet so surrounded with mystery, that it is impossible to indicate the part played by the various glands engaged in the process; but it is not improbable that the suprarenal capsules may play a prominent part, either actually by secretion of pigment, or by allowing it to accumulate in the blood. This theory will not, however, solve the intricacies of the question; for the appearance of pig. ment in the feetus, under ordinary circumstances, at the age of six or seven weeks, and before any organ can have attained to a sufficiently advanced stage of development to exert any material influence, must make us look for some more antecedent condition.

The case stands thus. IVe find both father and mother deeply pigmented ; and the foetus, which is deriving its support from the blood of the mother, destitute of pigment. What inference can we deduce from this fact? Why this-either that the placental vessels, from some disease or other cause, will not permit of the transudation of pigmental materials; or that the cells destined in the fotal structure to take up the materials, are unable to do so. Careful observation may some day illuminate this intricate question. The process of pigmental secretion does not probably differ much from the secretion of fat, and people are dark or fair for the same reason that they are fat or lean; in the one case the pigment, in the other the fat-cells, being in excess; although doubtless one secretion is of much greater importance in the economy
than the other.

Whether this condition was to be looked upon as a disease or a natural phenomenon giving rise to a variety of the human race, was at one time the subject of active controversy. In coming to a conclusion upon this point, every one will be guided by the meaning which he places upon the terms natural and morbid. If we look upon the congenital absence of the iris, the lens, or any other organ, as a disease, we must take the same view with regard to the absence of pigment or the cells which secrete it, although it may not be productive of an equal amount of inconvenience. Every circumstance that mars the form or function of the human frame, I consider, may be accounted as a disease; and the fact that its reproduction is certain, as the result of the connexion of two individuals affected with the same peculiarity, does not put it beyond the bounds of such a classification.
When we consider the many structures in which pigment is invariably present, we cannot but consider that its absence must be attended with a certain amount of deterioration in the function of those structures. Thus it enters to a considerable extent into the formation of nerves, and especially their ganglia; and most unequivocally these organs suffer in the albino. Although not deficient in intellect, they rarely equal in this respect their more fortunate fellows. In phy. sical strength or nerve-powers, they are decidedly deficient. One curious point, which should not be overlooked, is the constant oscillation of the eyes; and, when we consider that the third nerve, which presides over their movements, takes its origin in the locus niger of the crus cerebri (normally the most deeply pigmented portion of the nervous system ), this symptom, which is rarely absent, becomes of peculiar interest.

$\mathrm{J}$. and A., aged respectively 3 and 5 years, were born and live in Newcastle-upon-Tyne.* They belong to a family of nine children, eight of whom are alive. The places they occupy in the family are those of fifth and seventh child. Their mother has dark-brown hair and dark-brown irides. Their father is also a dark man. Their grandparents on the mother's side exhibited no unusual appearances, being both moderately dark on the father's. Beyond this, their pedigree cannot be traced; but there is no reason to suspect albinism in any of their ancestors. Both these children possess extremely fair skins, milk-white hair, and most peculiar reddish deflexion from the fundus of the eye, etc. - characteristic of their condition. They are well-grown children, with fair muscular development, and by no means deficient in intelligence, although not equal in this respect to their brothers. In temperament, their mother says, there is nothing peculiar to them, except, perhaps, that they are more greedy than the other children, and require usually a larger quantity of aliment. It has been stated that albinos are unusually active during the night; hence they are called nocturnal men. But in the present instance there seems no such tendency, and the children sleep as well as their fellows. During the day, they run about and play like their companions; but their sight is evidently defective ; one of them (the younger) always closes one eye in regarding objects. Both of them are troubled by a bright sunshine, and try to avoid it; and they have a constant oscillation of the globes, such as we frequently see in congenital cataract. The elder boy goes to school, and has acquired a knowledge of letters, which enabled me to test accurately his power of vision. At a distance of twenty feet, he can make nothing out of the largest test-type. Glasses do not improve his vision; nor does a stenopoic apparatus.

$$
\begin{aligned}
& \text { For distance, } V=\frac{10}{\mathrm{Cc}} \text {. } \\
& \text { For near, } V=\frac{1}{I V \frac{1}{2}} \text {. }
\end{aligned}
$$

He cannot distinctly see any smaller type. When reading, he generally holds the book very close, contracting the eyelids like a person who is myopic.

It is generally supposed that albinos possess unusual powers of vision in obscure light. I do not find this to be the case with these childrer, but rather the contrary; for, although a strong light dazzles and irritates them, their vision in the deeper shades of darkness was not so acute as my uwn. This I verified on several occasions; and one of them expressed of his own accord that he could see infinitely better with the blind up in the room than when it was down.

This total absence of pigment from the structure of the eye gives a most remarkable appearance to the fundus. It prevents the margins of the disc from being visible, and brings into relief as strongly the vessels of the choroid as those of the retina. Hence the appearance is that of a beautiful white ground, intersected by myriads of small vessels; the retinal arteries and veins being only distinguished by their increased size and their direction.

When looking at the part of the fundus which occupies the neighbourhood of the macula, the appearance is that of a perfect blaze of scarlet, in which no outline of vessels is completely made out ; and this increased area of vascularity is tolerably abruptly limited. Jäger, in his Atlas of Ophthalmoscopy, gives the drawing of the fundus of an albino which in no way corresponds to the appearance in this case. I cannot help thinking that the subject from whom it was taken was not a perfect albino.

The observations recorded above show, I think, that the absence of pigment in the choroid interferes less than has been supposed with the optical purposes of the eye ; for if the amblyopia was to any extent dependent upon this, we should expect material improvement with the use of stenopœic spectacles, and I am inclined to attribute the deterioration of sight chiefly to impairment of the nervous centres through want of pigment.

* Since this paper was written, another albino child $\mathrm{r}$ as been born of the same 